\title{
Quem controla a política de ninguém? Anonymous Brasil e o ativismo hacker nas redes de comunicação ${ }^{1}$
}

\section{Who control the politics of no one? Anonymous Brazil and hacktivism in communication networks}

\author{
Bárbara Maria Farias Mota* \\ Dalson Britto Figueiredo Filho*
}

\begin{abstract}
Resumo: Esse artigo analisa a atuação política dos hackers a partir de um estudo de caso da rede Anonymous Brasil, uma das vertentes do hacktivismo no contexto brasileiro. Para tanto, utiliza as postagens de um dos diferentes perfis Anonymous no Twitter, no período da Operação Hacking Cup (\#OpHackingCup), que consistiu em uma série de protestos virtuais contra a Copa do Mundo de 2014. Metodologicamente, o desenho de pesquisa adota uma abordagem multimétodo, unindo análise de conteúdo e estatística descritiva. Os resultados evidenciam que por meio da utilização de ferramentas digitais transgressivas e do anonimato, esses atores não estatais evidenciam táticas estratégicas de ação diante do controle/vigilância presentes na sociedade contemporânea.
\end{abstract}

Palavras-chave: Anonymous Brasil. Ativismo hacker. Redes informacionais.

\begin{abstract}
This article analyses the political actuation of hackers from a study case of the Anonymous Brazil network, one of the faces of hacktivism in the Brazilian context. For such, this paper utilises tweets from one Anonymous profile in Twitter, during the period of the Operation Hacking Cup (\#OpHackingCup), which entailed several digital protests against the 2014 World Cup. Methodologically, this paper adopts a research design based on a multi-method approach, uniting content analysis and descriptive statistics. The results show that, by the means of transgressive digital tools and anonymity, those actors spotlight strategical tactics as a countermeasure to the control/surveillance that is present in the contemporary society.
\end{abstract}

Keywords: Anonymous Brazil. Hacktivism. Informational networks.

Lugar nenhum é onde estamos \#OpHackingCup \#OpWorldCup

Tweet da @AnonBRNews (Anonymous Brasil).

Recebido em: 29/06/2015. Aceito em: 25/04/2016.

\footnotetext{
${ }^{1}$ Este artigo é resultado do trabalho "Quem controla a política de ninguém? Anonymous Brasil e o hacking político nas redes digitais de comunicação", e contou com o apoio financeiro do Programa de Educação Tutorial de Ciências Sociais da Universidade Federal de Pernambuco (UFPE) através da Secretaria de Ensino Superior do Ministério da Educação (MEC, SESu). Agradecemos, em especial, aos membros do grupo de Métodos de Pesquisa em Ciência Política da UFPE pelas contribuições trazidas a pesquisa. Eventuais erros e demais inconsistências na redação final do artigo são de responsabilidade exclusiva dos autores.

" Mestranda em Sociologia e Bacharela em Ciências Sociais pela Universidade Federal de Pernambuco (UFPE). Atualmente é integrante do Grupo Métodos de Pesquisa em Ciência Política (DCP/UFPE), Recife - Pernambuco - Brasil. E-mail: barbarafmota@gmail.com.

${ }^{*}$ Professor de Ciência Política da Universidade Federal de Pernambuco (DCP/UFPE), Doutor e Mestre em Ciência Política pelo Departamento de Ciência Política da Universidade Federal de Pernambuco (DCP/UFPE). E-mail: dalsonbritto@yahoo.com.br.
} 


\section{Introdução}

A popularização da Internet permitiu a democratização das possibilidades de ativismo político transnacionalmente. Por outro lado, ampliaram-se também as potencialidades de captação da inteligência coletiva presente na rede, tornando difícil e improvável, não ser rastreado ou ter o tráfego de navegação analisado por órgãos de governos e por empresas.

Desse modo, na medida em que os Estados se fundem com a rede e ampliam o seu poder de controle sobre as informações, as relações de força necessitam de novas configurações (ASSANGE et al, 2012). Em face disso, hackers e programadores representam atores privilegiados para o ativismo na Internet devido ao seu conhecimento avançado da linguagem computacional (SILVEIRA, 2009). Isso porque na sociedade informacional, aqueles que escrevem códigos e manipulam formatos digitais detêm uma posição estratégica para influência política, já que essas instruções na esfera virtual exercem a mesma função das leis determinando as nossas ações (LESSIG, 1999). Diante disso, é importante questionar também o papel do anonimato como estratégia de resistência à vigilância eletrônica em massa.

Como atores não identificados civilmente utilizam as redes digitais para o ativismo político? Esse artigo analisa a atuação política dos hackers, também denominada de ativismo hacker ou hacktivismo. O principal objetivo é descrever como os Anonymous Brasil atuam politicamente na Internet. Em particular, investigar como a adesão ao anonimato evidencia táticas estratégicas de ação nas redes informacionais. O objeto de estudo é a rede Anonymous Brasil2, uma das principais vertentes do ativismo hacker no contexto brasileiro. Mais especificamente, a unidade de análise repousa sobre a atuação dessa rede na Operação Hacking Cup (\#OpHackingCup). Tal Operação foi articulada pela AnonBRNews, uma das diferentes células que se autodenomina Anonymous Brasil, e consistiu em uma série de

\footnotetext{
${ }^{2}$ A rede não é composta majoritariamente por hackers. Também há artistas, ativistas, escritores, estudantes, dentre outros com ou sem conhecimentos técnicos mais robustos. No entanto, este trabalho se foca na vertente hacktivista.
}

protestos virtuais contra a Copa do Mundo de 2014.

Mas por que investigar a ação política dos hackers? Em primeiro lugar, a maior parte da literatura sobre o assunto foi produzida para o contexto norte-americano (COLEMAN, 2012; MILAN, 2013; OLSON, 2014; SAMUEL, 2004; VEGH, 2003; WRAY, 1998). Comparativamente, os estudos sobre o ativismo hacker no Brasil ainda são reduzidos (LEMOS, 2002; PARRA, 2012; SILVEIRA, 2010). Em particular, sobre os Anonymous Brasil, salvo melhor catalogação, há apenas o trabalho de Machado (2013). Desse modo, a presente investigação se mostra relevante por dois principais aspectos: 1) trazer contribuições às teorias da ação coletiva e do hacktivismo como objeto de estudo; e 2) evidenciar as potencialidades e limitações do anonimato como estratégia política.

Para tanto, o desenho de pesquisa examina o conteúdo das mensagens do Anonymous Brasil, no Twitter, entre maio a julho de 2014 , período que compreende a mobilização e dispersão da operação investigada. Para obter todos os tweets da célula @AnonBRNews fez-se o emprego das API's ${ }^{3}$ do Twitter. Para tanto, foi utilizado um programa ${ }^{4}$ para automatizar o processo de captura dos dados e geração da planilha com descrição dos tweets, data, hora, quantidade de retweets (alcance de um tweet) e de favoritos (quantidade de vezes que um tweet foi favoritado). No total 547 tweets foram categorizados e codificados.

O artigo está dividido do seguinte modo: a primeira seção discute o ativismo hacker na perspectiva da desobediência civil eletrônica e contextualiza a relação entre esse tipo de ação e o anonimato nas redes digitais. A segunda evidencia a emergência da rede Anonymous no cenário político mundial. Mais especificamente, discute as ações de grupos Anonymous brasileiros. A terceira seção sumariza os procedimentos metodológicos da pesquisa. A quarta apresenta

\footnotetext{
${ }^{3}$ Application Programming Interface (Interface de Programação de Aplicativos). Mais informações sobre API's do Twitter em: <https://dev.twitter.com/docs/api/1.1>.

${ }^{4} \mathrm{O}$ programa foi desenvolvido especialmente para este trabalho e pode ser rodado em qualquer interpretador Python. Está disponível para livre utilização, modificação e redistribuição em: https:// github.com/x8lucas8x/yatufc.
} 
os resultados empíricos do trabalho. Por fim, são trazidas as considerações finais da pesquisa.

\section{O ativismo hacker e a desobediência civil eletrônica}

O uso político da Internet desponta na década de 1990 com a popularização da Web. Em 1994 os zapatistas utilizaram a rede para tecer um novo modo de resistência e disseminação das suas reivindicações para além das fronteiras do México - sem a intermediação e restrição dos meios de comunicação comerciais - como a Televisa, estação de TV controlada pelo governo e campeã de audiência no país (CLEAVER, 1998). Um dos desdobramentos do ciberzapatismo ocorreu em 1999, quando das manifestações contra o encontro da Organização Mundial do Comércio (OMC), quando ocorreu a adesão de ativistas em âmbito local e global mobilizados por meio das redes digitais.

De acordo com Milan (2013) a ascensão do ativismo hacker - um tipo peculiar de ciberativismo - igualmente se beneficiou do baixo custo, velocidade e flexibilidade da comunicação para reivindicações sociopolíticas. Ao recorrer a Distúrbio eletrônico, famosa publicação do coletivo de artistas Critical Art Ensemble (CAE) que teoriza a desobediência civil eletrônica, a autora afirma que:

Em meados de 1990, a Critical Art Ensemble (CAE) teorizou que a desobediência civil eletrônica é a forma de resistência política mais significativa em tempos de poder nômade e descentralizado (Critical Art Ensemble, 1993 and 1996). De acordo com o CAE, o distúrbio eletrônico não foi um movimento de massa, mas sim um meio de intervenção baseado em células e caracterizado por ações bate-e-corre, os quais tiravam vantagem da descentralização típica da sociedade da informação. Em 1996, o grupo baseado no Texas conhecido como Cult of the Dead Cow cunhou o termo hackerativismo, para descrever o vasto conjunto de atividades que se enquadram tanto em ativismo quanto hackeamento, de forma a indicar o uso de expertise técnico como a programação motivado politicamente (MILAN, 2013, p.05).

Nessa perspectiva, um dos marcos do hacktivismo ocorreu em 1998, quando o Eletronic
Disturbance Theater (EDT), grupo dissidente do CAE, impulsionou uma batalha digital por meio de ações de negação de serviço (DDoS) ${ }^{5}$ aos sítios governamentais do México em apoio ao movimento zapatista (WRAY, 1998). Segundo Machado (2013), é nessa época que muitos grupos ficaram conhecidos por suas ações de paródias virtuais, desfiguração de páginas (deface $)^{6}$ e interceptação de dados nas redes digitais de comunicação.

Essas atividades são compreendidas por Samuel (2004) como a junção entre o ativismo político e o hacking de computador, através do uso não violento e legalmente ambíguo de ferramentas digitais com finalidades políticas. A autora as identifica como um tipo de desobediência civil eletrônica na medida em que há o uso transgressivo de ferramentas digitais como: desfiguração de sites, redirecionamento de páginas, negação de serviço, roubo de informações sigilosas, paródia de sites, manifestações virtuais; sabotagens virtuais e desenvolvimento de softwares. Desse modo, essas práticas se diferenciam das ações ciberativistas comuns (petições online, votações online, fóruns etc.), que se encontram nos limites convencionalmente aceitos da atuação política, e das atividades ciberterroristas, que fazem o uso da violência para atingir objetivos (idem, 2004).

Vegh (2003) também reforça a leitura dessas ações pela perspectiva da desobediência civil eletrônica e compreende a adoção de causas políticas por parte dos hackers para justificar as suas atividades, sendo: "o hacktivismo uma ação online politicamente motivada, ou uma campanha de ações, realizada (s) por atores não-estatais em retaliação para expressar desaprovação ou

\footnotetext{
${ }^{5}$ Acrônimo para Distributed Denial of Service, também conhecido por ação de negação de serviço. É a sobrecarga de um site proveniente de múltiplas entidades computacionais simultâneas esgotando a capacidade de processamento do servidor que hospeda a página. Tem similitude com um protesto na rua à medida que, como forma de contestação, ocupa e obstrui um espaço virtual impossibilitando outras pessoas de utilizá-lo.

${ }^{6}$ Também é conhecido como "grafiti online". Por meio das falhas de segurança no servidor que hospeda um site, é possível ter acesso ao servidor e alterar os arquivos que compõem a página, provocando modificações na sua aparência ou no seu funcionamento. O deface pode estar relacionado tanto ao prestígio pessoal na medida em que um hacker consegue se apropriar de uma página e evidenciar suas falhas de segurança ou pode disseminar um conteúdo de cunho político, a exemplo da substituição da página do Ministério da Defesa do Governo da Síria em protesto de apoio aos cidadãos do país, em 2011
} 
para chamar a atenção a uma questão defendida pelos ativistas" (2003, p.167).

Marion e Goodrum (2000), por sua vez, formulam as condições necessárias e a justificação ética para que essas ações sejam classificadas como atos de desobediência civil eletrônica, a saber: 1) não causem dano a pessoas ou a propriedades; 2) não sejam violentas; 3) não sejam desempenhadas visando o lucro pessoal; 4) tenham motivações éticas, consistindo na convicção de que a lei, norma ou conduta contra a qual se protesta é injusta; e 5) tenham por parte de quem exerce essas ações, uma vontade de assumir as responsabilidades pessoais para as eventuais consequências (MACHADO, 2013; MARION e GOODRUM, 2000).

Nessa perspectiva, o ativismo hacker desponta como um modo de resistência no contexto de vigilância eletrônica global, pois os hackers conseguem embaralhar dados e apagar os seus rastros, gerando prejuízos ao exercício do controle nas redes digitais (SILVEIRA, 2009). Baseado nisso, Machado (2013) afirma que não se trata de desenvolver táticas por fora da esfera dos protocolos (que determinam padrões técnicos necessários para estabelecer a comunicação em rede), mas de uma forma de engajamento projetada no interior dessa própria esfera, permitindo aos hacktivistas resistirem, ludibriarem e hipertrofiarem o controle. Por controle, Silveira (2012) compreende a capacidade que algo ou alguém possui de exercer fiscalização, monitoramento, regulação ou domínio da ação de objetos ou seres vivos. Ele caracteriza os quatro principais tipos de controle exercido na sociedade informacional, seguidos de suas finalidades, a saber: protocolos, que gerenciam a comunicação na rede; formatos, que respondem pela memória e pelo modo de armazenamento dos dados digitais; linguagens de programação, que definem as formas como vemos e organizamos os nossos desejos na rede; rastros de navegação, que são a base das atividades que fazemos no ciberespaço; e acesso, responsável pela permissão ou bloqueio das plataformas informacionais (idem, 2012).

Diante da ampliação das possibilidades de controle/vigilância, a discussão sobre o hacktivismo tem um papel fundamental também para compreensão do anonimato como estratégia política, já que ambos vão de encontro à apropriação da inteligência coletiva na rede. De acordo com
Silveira (2009) o anonimato é a condição da comunicação não-identificada sendo exercida por interagentes que não possuem uma identidade explícita ou que a ocultam no espaço virtual. Por isso, a capacidade para dificultar o rastreamento nas redes informacionais está cada vez mais associada ao próprio controle dos dados pessoais. Isso, por conseguinte, se relaciona à anonimização, pois o controle é avesso a tudo aquilo que seja anônimo, incerto ou nômade (idem, 2009).

Wong e Brown (2013) evidenciam que atores políticos não estatais, tais como os Anonymous e o Wikileaks ${ }^{7}$, são ativados pela potencialidade do anonimato na Internet. É justamente por isso que esses atores afetam as formas contemporâneas de se pensar o ativismo global ao se engajarem no que os autores classificam de "a política de ninguém". Ou seja, as tecnologias informacionais não são apenas um meio para tomada de decisões políticas como também reconfiguram o próprio modo como a política se expressa:

[...] O potencial de anonimato da Internet permite a emergência de diferentes tipos de protestos sociais. Ao contrário dos protestos físicos como uma demonstração de força, ativistas podem se reunir online, às vezes deliberadamente, às vezes acidentalmente, e expressar suas preferências políticas através do vazamento de informações ou atacando servidores (WONG e BROWN, 2013, p.1024).

Assim, através de protestos virtuais, esses atores fazem exigências sem revelar quem são (o quem importa menos que o como), impondo custos físicos sem deixar vestígios no espaço físico, quando, por exemplo, documentos sigilosos de autoridades públicas são vazados. Os autores ressaltam ainda que a classificação desses atores como grupos terroristas mostra-se inadequada, pois o terrorismo é definido na literatura por ações de violência física e/ou psicológica contra civis, implicando em potenciais danos físicos ou na morte destes. Assim, ainda que esses atores se envolvam em atividades questionáveis legalmente, agem com fins ideológicos e políticos de

\footnotetext{
7 Organização dedicada à publicação de documentos secretos que denunciam a conduta indevida de governos, empresas e instituições. O WikiLeaks se destacou em 2010, com o vazamento em massa de mais de 75 mil diários militares sobre a guerra do Afeganistão e 251.287 comunicados diplomáticos de 274 embaixadas dos EUA (ASSANGE et al, 2012).
} 
mudança. Portanto, eles se distinguem das redes criminosas ou terroristas já que a violência física não faz parte das suas táticas de ação e as suas motivações não operam para o lucro pecuniário.

\section{Anonymous: "Nós somos a legião"}

Machado (2013) evidencia que as atividades hacktivistas passaram a ter pouca notoriedade após o dia 11 de setembro de 2001, quando da ocorrência dos ataques contra as Torres Gêmeas nos Estados Unidos. Nessa época, os discursos sobre os hackers na grande mídia passam a retratá-los não só como cibercriminosos comuns, visão popularmente atrelada a esses indivíduos, mas também como ciberterroristas. Em decorrência disso, a criminalização do hacktivismo e o combate ao anonimato na navegação em rede foram intensificados (VEGH, 2003). Isso se tornou mais evidente quando da aprovação do Ato Patriota norte-americano ${ }^{8}$ nesse mesmo ano, ampliando os mecanismos de vigilância do Governo, muitas vezes sem respaldo legal ou suspeitas fundamentadas, supostamente em nome da "Guerra contra o terror". Em decorrência disso, as ações hacktivistas passaram a ser desencorajadas por seus praticantes, ressurgindo apenas em 2008 no cenário político mundial quando os Anonymous ganharam visibilidade (MACHADO, 2013).

Os Anonymous são uma rede (composta por várias outras redes) ou um modo de ação hacktivista que utiliza as tecnologias digitais para defesa de causas sociais, da transparência de Estados e empresas, da salvaguarda da privacidade e do compartilhamento de bens simbólicos. Os ideais norteadores de suas táticas partem dos pilares da cultura hacker: liberdade de expressão e emancipação dos indivíduos pelo acesso irrestrito à informação. Nesse sentido, os Anons reivindicam a transparência dos que estão no poder e o anonimato como arma política para garantia da privacidade dos que não estão. Tal concepção se associa a outro princípio da ética hacker: não importa quem você é, mas o que você faz. Ou seja, os "hackers devem ser julgados por seus hackeamentos e não por outros critérios,

\footnotetext{
${ }^{8}$ Lei $n^{\circ}$ 107-56/2001. Disponível em: http://www.fincen.gov/statutes_regs/patriot/.
}

tais como escolaridade, idade, raça ou posição social" (LEVY, 2010, p.31).

Apesar da adesão a uma identidade coletiva anônima sob a máscara de Guy Fawkes ${ }^{9}$, não se trata de um movimento ou de um grupo homogêneo de indivíduos. Nas palavras de Machado (2013):

Trata-se, antes disso, de uma ideia e uma forma de ação compartilhados por uma ampla, difusa e heterogênea rede de grupos e indivíduos atuando em todo o mundo. Por se tratar de uma ideia, não conta com donos, liderança central e muito menos centro geográfico. Da mesma forma, para aderi-la, não é preciso pedir permissão ou passar por qualquer tipo de processo seletivo. Justamente por isso, muitos se dizem Anonymous, mas ninguém se diz do (a) Anonymous (MACHADO, 2013, p.23).

De acordo com Coleman (2012), os Anonymous não têm uma filosofia ou um programa político consistente e agem também apenas pela diversão: "movidos por uma vontade coletiva dirigida para travessura - para o Lulz, uma distorção bastarda da abreviatura LOL [...]. O Lulz representa tanto um etos como objetivo" (COLEMAN, 2012, p.93). Além disso, a autora evidencia que o método de ação política desse coletivo emerge em 2008, numa Operação deflagrada contra a Igreja da Cientologia norte-americana (\#OpChanology). Após a tentativa de censura, por parte da Igreja, ao vazamento de um vídeo produzido para seu público interno, um grupo de usuários de um popular fórum de imagens denominado $4 c h a n^{10}$, articulou uma série de ações de protestos contra essa instituição religiosa através do uso de ferramentas digitais e de ações diretas nas ruas.

No entanto, os Anonymous ganham destaque no cenário político mundial em 2010 após o ciberataque (\#OpPayBack) que culminou na derrubada dos sites do Paypal, Mastercard e Visa, instituições financeiras responsáveis pelo

\footnotetext{
${ }^{9}$ Soldado que tentou explodir o parlamento inglês no séc. XVII em episódio que ficou conhecido como "Conspiração da pólvora". Guy Fawkes inspirou a criação do personagem $V$ de Vingança dos quadrinhos de Allan Moore. Devido à popularização do filme de mesmo nome, a máscara passou a ser adotada pelos Anonymous.

${ }^{10}$ Uma das principais características desse fórum era o anonimato compulsório dos usuários.
} 
bloqueio de donativos direcionados ao WikiLeaks. Desde então, as ações de DDoS se tornaram uma das táticas mais recorrentes da rede como forma de protesto (COLEMAN, 2012; OLSON, 2014). Segundo Coleman (2012), essas atividades são mal definidas no plano legal e moral, pois ora se configuram como atos pacíficos e lícitos, ora são considerados como perturbadores e ilícitos. Isso porque as ações de $D D o S$, por exemplo, têm similitude com um protesto no espaço físico à medida que, como forma de contestação, ocupa e obstrui um espaço virtual impossibilitando outras pessoas de utilizá-lo. A figura 1 ilustra essa alusão:

Figura 1 - Alusão a uma Ação Distribuída de Negação de Serviço (DDoS)

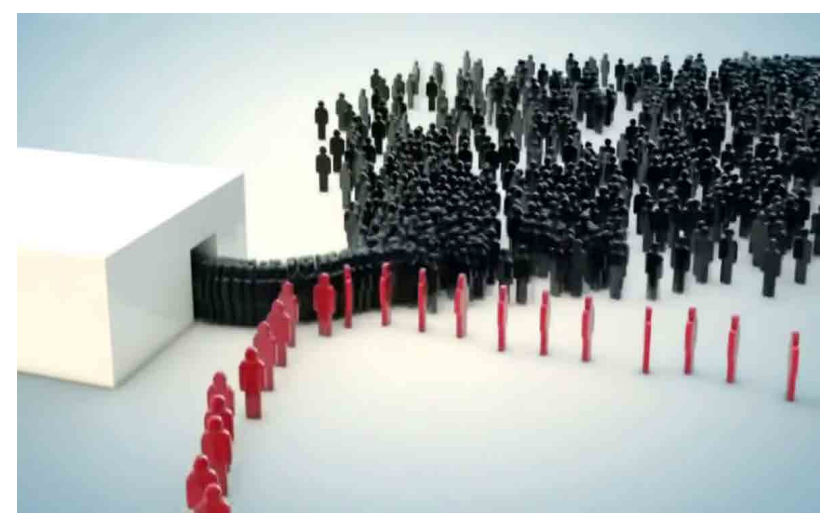

Fonte: Documentário We are Anonymous - The Story of The Hacktivists

A Operação Payback (\#OpPayback) evidenciou também uma das táticas de engajamento político dos Anons: a articulação e divulgação de Operações (que abarcam propósitos diversos) em sites de redes sociais (Facebook e Twitter) e na AnonOps, rede de IRC - em que há salas de bate-papo exclusivas para as ações do coletivo (MACHADO, 2013; OLSON, 2012). Essas operações se constroem na mesma velocidade com que se desfazem. As salas de bate-papo da AnonOps são utilizadas para comunicação interna e para definição de pautas e de alvos ${ }^{11}$. A mobilização é feita nas redes sociais e serve para a comunicação externa com o público, incentivando a produção e a replicação de conteúdos do coletivo (vídeos com chamadas para as
Operações (\#Op), memes, sites derrubados ou desfigurados, dossiês, dentre outros). Essas mobilizações são conexões temporárias que partem da ideia de que cada indivíduo é um potencial veículo midiático. Esta é uma estratégia típica das mídias táticas ("faça você mesmo") e facilmente autopropagáveis- difíceis de serem combatidas ou controladas por serem desterritorializadas e desprovidas de lideranças centrais.

Ao descreverem o poder de autopropagação de organizações sem líderes, Brafman e Beckstrom (2007) recorrem aos estudos de Nevins (1945) para explicar como a forma de organização societária das tribos Apache permitiu a sua resistência frente ao controle do exército espanhol, em 1670. Para os autores, eles conseguiram resistir porque distribuíam o poder político, isto é, havia pouca centralização nas tomadas de decisões. Não havia lideranças centrais determinando o que deveria ser feito, mas antes disso, existiam os chamados catalisadores: pessoas que "lideravam" pelo exemplo e não pela autoridade. Desse modo, quanto mais os Apache eram atacados mais se dispersavam territorialmente, tornando difícil a sua cooptação. Em alusão a eles, os autores afirmam que numa organização centralizada, há indivíduos dando as ordens e um local físico para as tomadas de decisões (O CEO de uma empresa, por exemplo). De modo que é necessária a aplicação de regras para eficiência do sistema, mas o poder é centralizado e frágil quando na ausência do líder. Já em organizações descentralizadas, o funcionamento não é pautado pelas lideranças, hierarquias ou sedes. E quando há um "líder", é igualmente o catalisador influenciando outras pessoas por meio do exemplo a tomarem determinadas decisões. O quadro 1 sumariza a rede Anonymous a partir do modelo de Brafman e Beckstrom (2007):

\footnotetext{
${ }^{11}$ Alvo aqui se refere aos sites que sofrerão tentativa de hackeamento.
} 
Quem controla a política de ninguém? Anonymous Brasil e o ativismo hacker nas redes ...

Quadro 1 - Anonymous

\begin{tabular}{|c|}
\hline Ninguém está no comando \\
\hline Não há sedes \\
\hline Se você atingir uma célula a ideia sobreviverá \\
\hline Há uma divisão heterogênea de funções \\
\hline Se você retira uma unidade, a rede não é afetada \\
\hline Conhecimento e poder são distribuídos \\
\hline A rede é flexível \\
\hline As células são autofinanciadas \\
\hline Não é possível contar o número de participantes \\
\hline Grupos se comunicam diretamente entre si \\
\hline
\end{tabular}

Fonte: elaboração dos autores a partir de Brafman e Beckstrom (2007).

\section{Anonymous Brasil}

Ainda que embrionários no cenário político nacional, os Anonymous Brasil tiveram ápice em Junho de 2013 quando eclodiram inúmeras células se reivindicando Anonymous ${ }^{12}$ e convocando, por meio das redes digitais, a população para os protestos nas ruas. De acordo com Pimentel e Silveira (2013), não havia concentração representativa em lideranças centrais e as ações indicaram um padrão de mobilização fora das instituições políticas. Após a realização de uma pesquisa baseada em uma amostra de comentários do Facebook, em Junho de 2013, Silveira (2013) constatou os Anonymous com os maiores focos de atividades nessa rede social nas datas em que os protestos tiveram grande repercussão nacional, como o dia 20: "Os Anonymous tiveram relevância na disseminação das informações e na articulação da solidariedade ao que era o movimento inicial pela redução das tarifas e contra a Copa. Eles foram decisivos. (SILVEIRA, 2013, online)".

Mas antes disso, é ainda na Operação Paypack (\#OpPayback) que as primeiras atividades de Anonymous brasileiros emergem (MACHADO, 2013). Essa Operação impulsionou os brasileiros a buscarem mais informações sobre as formas de engajamento em atos de apoio ao coletivo na Web. Ao analisar duas Operações capitaneadas em 2012 - Operacão WeeksPayment

\footnotetext{
${ }^{12}$ Esse ápice pode ser verificado através do Google Trends digitando-se os termos Anonymous Brasil no campo de busca, no período de 2013: https://www.google.com.br/trends.
}

(\#OpWeeksPayment) e a Operação Globo (\#OpGlobo), o autor constata quatro modos de engajamento político dos Anonymous brasileiros. A saber, 1) promoção do anonimato, que dentre outras coisas, consiste em um modo de engajamento no qual a invisibilidade individual potencializa a visibilidade coletiva e serve como uma ferramenta política para os que não estão no poder; 2) a evangelização, realizada por colaboradores identificados com a ideia Anonymous através da postagem de informações sobre a rede em blogs, sites, redes sociais etc.; 3) a formação de redes distribuídas, consiste na formação de várias redes independentes entre si. Isso porque há vários indivíduos $\mathrm{e}$, portanto, inúmeros métodos de ação estão envolvidos; e é uma forma de dispersar o poder, tornando difícil o controle das atividades por parte de agentes externos e 4) exibir e possibilitar várias formas de ações políticas. Isto é, por ser um coletivo desprovido de lideranças centrais, da existência de um núcleo geográfico e sem a necessidade de vínculos formais (vínculos frágeis e temporários são mais típicos), os Anonymous facultam o surgimento de várias táticas de ação. Essas táticas possivelmente são desconexas entre si, tais como as Operações, com objetivos e métodos de articulação que variam a depender do propósito (Ibidem, 2013).

\section{Procedimentos metodológicos}

Esse trabalho consiste em um estudo de caso sob a abordagem dos métodos mistos. Para Gerring (2012) um dos pontos positivos para adotar esse tipo de estudo é justamente o que se refere às pesquisas exploratórias. Um ponto negativo, por outro lado, é a incapacidade de produzir generalizações, embora seja passível de comparação com outros casos originados da mesma unidade analítica. Yin (2005), por sua vez, esclarece que um estudo de caso é adequado quando se dispõe - a partir da particularidade dos resultados encontrados - a gerar proposições teóricas que possam ser aplicáveis a outros contextos. Ele pontua que o estudo de caso não se propõe a generalização às populações e universos, mas antes disso, a geração de proposições teóricas que visam, posteriormente, à generalização analítica. Nessa pesquisa a unidade analítica consiste nos Anonymous Brasil. Desse modo, a 
lacuna teórica e empírica sobre o assunto em consonância com o baixo controle sobre um fenômeno contemporâneo situado num contexto específico, tal como os Anonymous Brasil na \#OpHackingCup, favoreceu adequadamente a escolha pelo estudo de caso. Isto porque contempla múltiplas fontes de evidências (YIN, 2005) em sites, redes sociais, repositórios de vídeos e salas de bate-papo. Além disso, a triangulação entre métodos quantitativos, qualitativos e os diferentes tipos de dados obtidos (FLICK, 2013), articula-se de maneira eficaz aos objetivos dessa proposta. O quadro 2 sumariza as principais características do desenho de pesquisa:

Quadro 2 - Desenho de pesquisa

\begin{tabular}{|l|l|}
\hline População & Coletivos Anonymous brasileiros. \\
\hline Período & De maio a julho de 2014. \\
\hline Fontes & $\begin{array}{l}\text { Perfil @AnonBrNews no Twitter; sala } \\
\text { de bate-papo: \#Ophackingcup na } \\
\text { rede AnonOps do IRC; repositórios de } \\
\text { vídeos de coletivos Anonymous Brasil } \\
\text { no Youtube e site da AnonBRNews. }\end{array}$ \\
\hline Técnicas & $\begin{array}{l}\text { Estatística descritiva e análise de } \\
\text { conteúdo. }\end{array}$ \\
\hline
\end{tabular}

Fonte: elaboração dos autores.

\section{Participantes da pesquisa e campo para coleta dos dados}

A população de interesse diz respeito aos coletivos Anonymous brasileiros no Twitter. Essa plataforma foi selecionada por ser um dos principais canais da rede para comunicação externa com o público. Ao contrário do Facebook, não é obrigatório ter uma identidade civil para a criação de um perfil no Twitter. Além disso, o algoritmo utilizado nessa rede não limita o alcance das postagens - como ocorre no Facebook ${ }^{13}$ - e permite que métricas como número de retweets e de favoritos sejam mais representativas.

\footnotetext{
${ }^{13}$ O EdgeRank é o algoritmo do Facebook que define o que será visualizado no Feed de notícias. A fórmula do algoritmo é concebida pelo tripé: afinidade: amigos e páginas que mais interagimos na rede; peso: quantidade de likes e compartilhamentos de determinados conteúdos e tempo de declínio: quanto mais tempo um post tiver sido feito, ele será colocado ao final do ranking do que aparecerá no Feed. No Twitter, as postagens que aparecem no Feed seguem uma ordem cronológica.
}

\section{Critérios de análise e instrumentos de coleta dos dados}

Primeiramente, foi feito um levantamento sobre os diversos coletivos que se reivindicam no Brasil como Anonymous. De acordo com Silveira (2014), só em 2013, ocorreu a eclosão de 178 coletivos. Após isso, foi feita a investigação sobre os coletivos com influência no período que precedeu a coleta dos dados, em meados de maio de 2014, privilegiando a possibilidade de observar uma Operação em tempo real. Nesse período, já havia especulações sobre a ocorrência de protestos online e offline contra a Copa do Mundo. Desse modo, foi feita uma busca com base em: matérias jornalísticas (localizadas pelo Google notícias ${ }^{14}$ ) que mencionavam os Anonymous Brasil e a articulação de protestos contra a Copa do Mundo de 2014. Posteriormente, foi feita uma pesquisa utilizando as hashtags: \#Anonymous, \#Brazil e \#Worldcup, no Twitter, com o objetivo de localizar o maior número de referências a uma mesma Operação. A busca remeteu a \#OpHackingCup ${ }^{15}$. Em um segundo momento, um grupo menor de perfis foi selecionado intencionalmente com base nos seguintes critérios: 1) quantidade de tweets; e 2) número de seguidores. Essa seleção evidenciou dois perfis mais influentes: @AnonBrNews e @ AnonymousBr4sil. Depois disso, optou-se por uma amostragem por conveniência que levou em conta o perfil mais apropriado para coleta dos dados nas circunstâncias do período da coleta. Um caso mais apropriado deveria permitir a coleta dos dados em tempo real ou em um curto intervalo temporal, haja vista as limitações das API's do Twitter ${ }^{16}$ e a imprecisão na ocorrência de Operações. Ambos os perfis eram apropriados tecnicamente. Embora o perfil @AnonymousBr4sil tenha um número de seguidores excedente ao da @AnonBrNews, existem inúmeras críticas (de pesquisadores e Anons) que evidenciam

\footnotetext{
${ }^{14}$ Disponível em: https://news.google.com.br/.

15 Embora a célula @AnonBrNews seja a referência na articulação dessa Operação, a escolha por este perfil para coleta dos tweets se justifica não só por isso, já que outros coletivos Anonymous também cooperam nas Operações.

${ }^{16}$ As requisições feitas às API's do Twitter abrangem no máximo os últimos 3200 tweets de um usuário. Por isso, o período de eclosão e ápice das diversas células Anonymous Brasil, Junho de 2013, não foi escolhido para investigação.
} 
a desvirtuação da ideia Anonymous por parte dessa célula. Em decorrência disso, o perfil @ AnonBRNews foi selecionado. Nessa perspectiva, reside uma limitação: 1) os tweets coletados são de um único perfil autodenominado Anonymous Brasil $^{17}$. Em seguida, o programa Yatufc ${ }^{18}$ foi utilizado para automatizar o processo de captura dos dados do perfil e para geração da planilha com a identificação do caso (Id), a descrição dos tweets, a data, a hora, a quantidade de retweets (alcance de um tweet) e de favoritos (quantidade de vezes que um tweet foi favoritado). No total, foram coletados 547 tweets veiculados pela célula @ AnonBrNews, aos quais estavam ou não vinculados, retweets e outros elementos interativos, tais como links externos. Os links que continham hiperlinks com imagens e vídeos foram armazenados para uma análise a parte. Os dados foram coletados através de duas requisições às API's do Twitter, delimitando para captura um período de três meses, entre maio de 2014 - mês de mobilização da Operação - a julho de 2014, mês de dispersão da Operação (após o encerramento dos jogos da Copa). Posteriormente, os dados foram processados através da biblioteca de análise de dados Pandas ${ }^{19}$ e parte dos gráficos foram gerados com auxílio da biblioteca de visualização Quadro 3 - Variáveis / Classificação dos Tweets

\begin{tabular}{|c|c|c|}
\hline Nome da variável & Classificação & Descrição \\
\hline Data & Data & $\begin{array}{l}\text { Data de postagem do } \\
\text { Tweet }\end{array}$ \\
\hline Hora & Hora & $\begin{array}{l}\text { Hora de Postagem do } \\
\text { Tweet }\end{array}$ \\
\hline $\begin{array}{l}\text { Número de } \\
\text { retweets }\end{array}$ & Número de retweets & $\begin{array}{l}\text { Número de vezes que o } \\
\text { Tweet foi retweetado }\end{array}$ \\
\hline $\begin{array}{l}\text { Número de } \\
\text { favoritos }\end{array}$ & Número de favoritos & $\begin{array}{l}\text { Número de vezes que o } \\
\text { Tweet foi favoritado }\end{array}$ \\
\hline Tweet & Conteúdo do Tweet & Conteúdo do Tweet \\
\hline \multirow[b]{2}{*}{ Links externos } & Sim & \multirow{2}{*}{$\begin{array}{l}\text { Tweet que remetia a } \\
\text { elementos interativos } \\
\text { ou não, tais como links } \\
\text { externos }\end{array}$} \\
\hline & Não & \\
\hline \multirow{4}{*}{ Classificação geral } & AssuntoCopa & \multirow{4}{*}{$\begin{array}{l}\text { Classificação geral do } \\
\text { assunto do Tweet de } \\
\text { acordo com a Copa, } \\
\text { a outros assuntos e a } \\
\text { Operações relacionadas } \\
\text { ou não a \#OpHackingCup }\end{array}$} \\
\hline & OutrosAssuntos & \\
\hline & OperaçãoECopa & \\
\hline & OperaçãoEOutrosAssuntos & \\
\hline \multirow{5}{*}{ Participação } & ConvocaçãoPresencial & \multirow{5}{*}{$\begin{array}{l}\text { Convocação para } \\
\text { presença em } \\
\text { manifestações virtuais e/ } \\
\text { ou físicas e cooperação } \\
\text { entre Anonymous } \\
\text { estrangeiros relacionados } \\
\text { ou não à \#OpHackingCup }\end{array}$} \\
\hline & E_Participacao & \\
\hline & Presencial_EParticipacao & \\
\hline & Cooperacaolnternacional & \\
\hline & Nenhum & \\
\hline
\end{tabular}

Fonte: elaboração dos autores
Semana e por Hora; Ranking das vinte Hashtags mais Mencionadas e Ranking dos vinte Perfis mais Mencionados ${ }^{21}$. Em outra planilha, os tweets foram classificados em categorias no intuito de identificar as informações relacionadas à Copa do Mundo, Operações e outros assuntos. Os dados foram tabulados e analisados utilizando os programas BrOffice.org Calc.3.2.1 $1^{22}$ e Statistical Package For Social Sciences (SPSS), versão $20^{23}$.

A tabela 2 sistematiza as variáveis de interesse e apresenta a sua descrição:

de dados Seaborn ${ }^{20}$, a saber: Frequência das postagens por dia; Total de Tweets por Dia da

\footnotetext{
${ }^{17}$ A despeito disso, é importante sublinhar que outros perfis também contribuíram com a Operação.

${ }^{18}$ Programa disponível em: https://github.com/x8lucas8x/yatufc.

${ }^{19}$ Biblioteca disponível em: http://pandas.pydata.org/.

${ }^{20}$ Biblioteca disponível em: https://github.com/mwaskom/seaborn.
} 


\section{Que os jogos comecem - Operação Hacking Cup (\#OpHackingCup)}

AOperação Hacking Cup (\#OpHackingCup), também denominada Operação World Cup (\#OpWorldCup) e Operação Mundial 2014 (\#OpMundial2014), consistiu em uma série de protestos virtuais que tirou do ar temporariamente, entre junho à julho de 2014, parte dos sites de domínio do Governo (.gov), das empresas patrocinadoras da Copa, dentre outros, manifestando ações contra a realização da Copa do Mundo de 2014 no Brasil.

Os motivos que levaram a ocorrência desses protestos foram evidenciados no vídeo de chamada para Operação24 publicado no Youtube (2014) antes do início do Megaevento esportivo:

[...] Não podemos mais aceitar passivamente às violações de direitos básicos resultantes da preparação para a Copa. Por preparação podemos entender: 1. higienização e elitização das cidades, expressas principalmente pela especulação imobiliária e pela violência contra a população em situação de rua que ocupa os grandes centros; 2. injustificáveis gastos para intensificar a segurança (e a repressão) contra as manifestações que possam vir a acontecer durante os jogos, aliada aos projetos de lei que marginalizam e criminalizam os manifestantes; 3 . garantir que ninguém -- a não ser os moradores da região e pessoas com ingressos -- se aproxime dos estádios em dias de jogo, além de que comércios não autorizados não abram horas antes e depois dos jogos, ainda que para isso seja necessário limitar a liberdade de ir e vir das pessoas, impedindo, por exemplo, que os moradores recebam visitas em suas casas; entre tantas outras violações. As ações online, assim como os protestos de rua, fazem parte de uma resistência contra esse modelo que se tornou tão evidente com os mandos e desmandos de uma megacorporação como a FIFA em nosso país, contra a influência do poder econômico nas decisões políticas e contra a priorização do lucro em contraponto aos direitos básicos de toda uma população; e, portanto, são legítimas. [...] Os olhos do mundo estarão voltados para o Brasil, mostraremos

\footnotetext{
24 “\#OpHackingCup - Que Os Jogos Comecem”, Youtube, 2014. Disponível em: <www.youtube.com/watch?v=|xHkMr2zn-8>. Acesso em: 14/06/2014.
}

para o mundo o quão farsante é e sempre foi o governo brasileiro e a FIFA.

O vídeo, finalizado com um dos famosos lemas do coletivo: "Nós somos Anonymous. Nós somos Legião. Nós não perdoamos. Nós não esquecemos. Esperem por nós.", foi replicado em diferentes redes sociais, inclusive por parte de outros perfis Anonymous (incluindo-se as células internacionais). Nessa produção são questionadas as decisões político-urbanísticas resultantes dos preparativos para a Copa, reivindicando-se a transparência dos gastos públicos nas intervenções espaciais ocorridas. Além disso, há uma forte oposição aos impactos sociais decorrentes disso, como é o caso das desapropriações para realização das obras de infraestrutura e a repressão de manifestações populares com respaldo legal, conforme disposto na Lei Geral da Copa. Convém expor que na sua versão em língua inglesa ${ }^{25}$, igualmente publicada pela AnonBRNews, há um maior quantitativo de visualizações. Isso se explica pela audiência da Copa do Mundo em âmbito global, o que acaba dando visibilidade à Operação e às demais formas de manifestações. Apenas a busca realizada no Google notícias, localizou 90 matérias sobre a OpHackingCup ${ }^{26}$, sendo o destaque para veiculação em meios de comunicação com grande repercussão internacional: BBC, Forbes, Reuters, Financial Times, ESPN e The New York Times.

É importante destacar que o título da postagem Que Os Jogos Comecem indica uma das características sobressalentes aos Anons: a ressignificação de conteúdos simbólicos pelo emprego da paródia ou da ironia, subvertendo os sentidos pretendidos na mensagem original. Notoriamente, a expressão jogos nesse contexto, se refere às atividades hacktivistas prestes a ocorrerem. Esse tipo de intervenção midiática também se associa a outro atributo dos coletivos Anonymous: o Lulz. Isto é, a diversão sentida em atividades de perturbação online, popularizada na gíria da Internet pelo "verbo" trollar. Em vários tweets da AnonBRNews, é possível localizar referências diretas ou indiretas a mensagens

\footnotetext{
${ }^{25} \mathrm{Na}$ última consulta, em 10/03/2015, constam 34.559 visualizações.

${ }^{26}$ Disponível em: http://goo.gl/li3nBv. Data da última visualização: $15 / 03 / 2015$.
} 
desse gênero, tornando tênue a distinção entre os conteúdos for the lulz (apenas para diversão) e as mensagens que denotam uma crítica política de modo irônico. Por exemplo, em uma das postagens que mencionam a polícia: "O mundo conhecendo nossa admirável polícia 27", há uma imagem denunciando a repressão policial ocorrida em uma manifestação na rua, seguida de links para o acompanhamento ao vivo dessa ação. A repressão policial também é ironizada em um meme, quando sua atuação é compreendida como show da copa. Em outro tweet: "\#OpHack ingCup \#OpWorldCup \#Deface no site da Glória Pires. Nada como assistir Além do Cidadão Kane diretamente pelo site de uma atriz da Globo ${ }^{28}$ ", ocorre a menção a um documentário de Simon Hartog, que denuncia o monopólio midiático da rede Globo e a sua influência na formação da opinião pública. Já em: "O sonho do hexa acabou, pois já se foram seis. Rumo ao HEPTA! ${ }^{29 ",}$ não há nenhuma crítica aparente, caracterizando uma mensagem carregada pelo espírito Lulz.

Com relação aos tweets coletados, primeiramente foi feito um levantamento das mensagens realizadas entre maio de 2014 - mês de mobilização da Operação, a julho de 2014, mês de dispersão da Operação, conforme ilustra a tabela 1:

Tabela 1 - Classificação geral das informações

\begin{tabular}{c|c|c}
\hline Conteúdo das mensagens & $\mathbf{N}$ & $\mathbf{\%}$ \\
\hline Copa & 195 & 35,6 \\
\hline Outros Assuntos & 146 & 26,7 \\
\hline Operação e Copa & 188 & 34,4 \\
\hline Operação e Outros Assuntos & 18 & 3,3 \\
\hline Total & $\mathbf{5 4 7}$ & $\mathbf{1 0 0 , 0}$
\end{tabular}

Fonte: elaboração dos autores.

Conforme esperado, a maior parte das mensagens está relacionada à Copa do Mundo $(35,5 \%)$. Sendo que $34,4 \%$ das postagens apresentam relação entre Copa e Operação. Ou seja, o quantitativo de mensagens condizentes a Copa

\footnotetext{
27 Id 397.

${ }^{28}$ Id 459.

${ }^{29}$ Id 518.
}

é ainda maior. Como havia outras Operações ocorrendo no período da coleta, os assuntos Operação e Copa nem sempre se vinculam diretamente, algo passível de ser questionado em decorrência do recorte metodológico (\#OpHackingCup). Além disso, muitas vezes as referências ao mundial condiziam às manifestações ocorridas no espaço físico, sem menções as hashtags ${ }^{30}$ que identificam a \#OpHackingCup. É importante constatar também um número significativo de postagens enquadradas em outros assuntos (26,9\%), indicando a utilização do perfil para pautar outras temáticas: denúncias de corrupção na Polícia Militar de São Paulo ${ }^{31}$; disputas entre perfis Anonymous ${ }^{32}$; publicização da ideia Anonymous ${ }^{33}$; desmilitarização da Polícia Militar ${ }^{34}$; repressão policial nas manifestaçõe ${ }^{35}$ e críticas a veículos midiáticos ${ }^{36}$. Isso confirma que o Twitter, além de uma plataforma para convocação e divulgação das manifestações (virtuais e físicas) contra a Copa, serviu aos propósitos de evangelização da ideia Anonymous, assinalando também um espaço para posicionamentos políticos.

Em relação à frequência das postagens, fica evidente que as atividades do perfil se intensificaram no período de Junho. O gráfico 1 apresenta essa informação:

\footnotetext{
${ }^{30}$ A hashtag é popularmente conhecida nas redes sociais pela inserção de uma palavra-chave precedida pelo símbolo da cerquiIha (jogo da velha). Isso transforma a palavra em um link clicável, permitindo a sua exploração por outras pessoas com interesses comuns. Trata-se, portanto, de um tipo de introdução ao conteúdo da mensagem.

${ }^{31}$ Id 348

${ }^{32}$ Id 06.

${ }^{33}$ Id 11.

${ }^{34}$ Id 15.

${ }^{35}$ Id 46.

${ }^{36}$ Id 438.
} 
Gráfico 1 - Frequência das postagens por dia

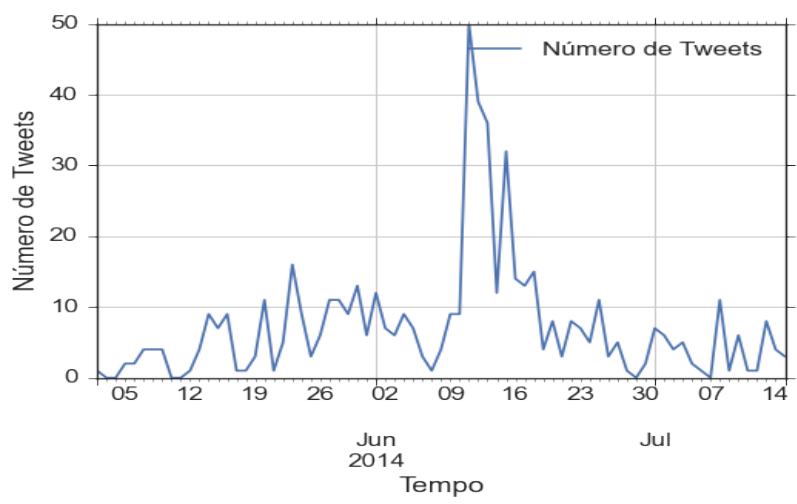

Fonte: elaboração dos autores

Desde o início do referido mês já havia menções à Operação e às manifestações contra a Copa, mas os picos das postagens ocorreram na quarta-feira, $11 / 06$, véspera do mundial, com a veiculação de 48 tweets e na quinta-feira, 12/06, estreia do mundial, com 38 postagens. $O$ domingo, 15/06, também apresenta um alto volume de postagens (31 tweets), em sua maioria retweets com conteúdos de outros perfis Anonymous. Quando se classifica o total das mensagens por dia da semana e por hora, é interessante constatar a maior parte das postagens concentradas em horários de jogos da Copa ${ }^{37}$ (tarde e noite). O gráfico de intensidade 2 ilustra essa informação:

Gráfico 2 - Total de Tweets por Dia da Semana e por Hora

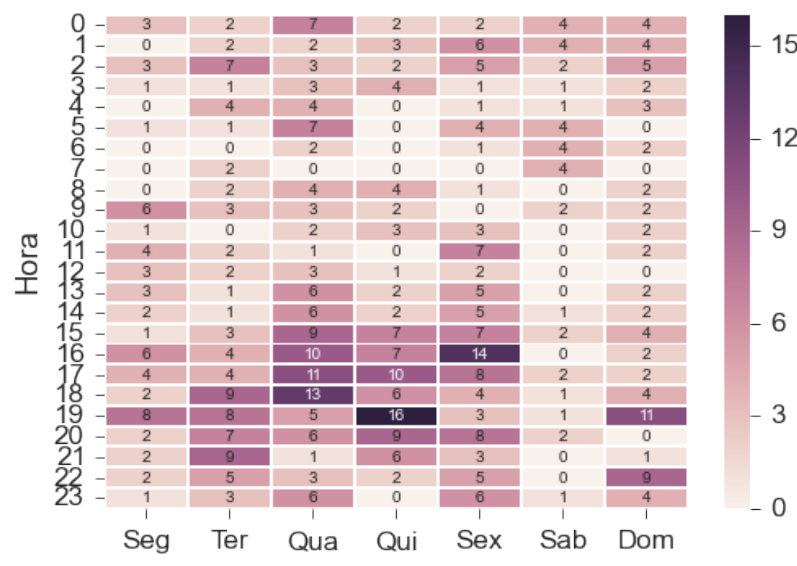

Fonte: elaboração dos autores

37 "Copa terá jogos à tarde e à noite". Disponível em: <http://www. abin.gov.br/modules/articles/article.php?id=9672>. Acessado em: $12 / 02 / 2015$.
É importante notar que há uma coincidência com os protestos ocorridos no espaço físico, que grosso modo, ocorriam em dias e horários das disputas dos jogos. Inclusive, muitas das postagens remetem a links com a cobertura em tempo real das manifestações nas ruas e fazem menção à expressão AO VIVO, a exemplo de: "Confiram ao vivo a manifestação Contra Copa em SP ${ }^{38}$." E "AO VIVO - Belo Horizonte - Policia Militar ataca ativistas - \#Avantelrmãos \#FIFAGoHome 39." Existem discrepâncias em alguns casos, há poucas postagens nos dias de sábados e domingos, embora com a ocorrência de jogos do mundial nesses dias.

Já no que consistem as 20 hashtags mais populares nesse período, há a recorrência de tópicos associados às atividades hacktivistas. O gráfico 3 ilustra essa informação:

\section{Gráfico 3 - Top 20 das hashtags ${ }^{40}$}

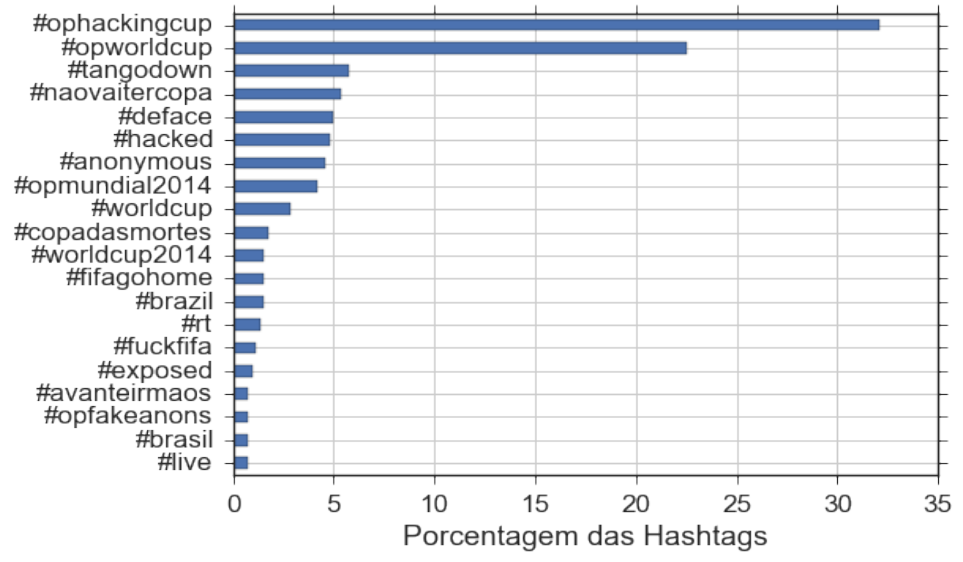

Fonte: elaboração dos autores.

Por exemplo, \#Tango Down (alvo caído) é uma expressão utilizada por hacktivistas quando ocorre uma ação bem sucedida de negação de serviço (DDoS). Essa hashtag, dentre as ações hacktivistas, é a mais citada (30 casos $/ 5,73 \%$ ) e geralmente está acompanhada de outras palavras-chave que identificam a Operação. Em segundo lugar vem \#Deface (desfiguração de

\footnotetext{
${ }^{38}$ Id 86.

39 Id 286.

${ }^{40} \mathrm{O}$ texto das hashtags foi transformado em letras minúsculas e teve as acentuações retiradas.
} 
página), com 26 casos (4,97\%). No entanto, esses números podem ser ainda mais expressivos já que \#Hacked ( 25 casos/4,78\%) se constitui em: DDoS, deface, leak ou exposed. Desse modo, quando uma página era derrubada $(D D \circ S)$ ou sofria uma desfiguração (deface), as publicações junto as hashtags, ora indicavam o link que remetia diretamente ao site-alvo e ora reportavam imagens para comprovação do ato. Nota-se também que as hashtags que se referem diretamente a Operação são claramente a maioria ${ }^{41}$, compreendendo respectivamente, \#OpHackingCup (168 casos/32\%) e \#OpWorldCup (118 casos/22,5\%). As hashtags que remetem indiretamente a Operação, aparecem pouco, respectivamente \#WorldCup (15 casos $/ 2,86 \%$ ) e \#WorldCup2014 (08 casos/1,5\%). A \#NaoVaiTerCopa (28 casos $/ 5,3 \%$ ), em geral, está vinculada aos protestos ocorridos presencialmente e também aponta para a cobertura feita por grupos de comunicação independentes, tais como a Mídia Ninja ${ }^{42}$.

A maioria das mensagens não apresenta convocação para as manifestações presenciais e/ ou físicas $(72,4 \%)$. E quando a cooperação entre Anonymous estrangeiros (10,8\%) é excluída, os chamados se direcionam para as manifestações presenciais $(7,9 \%)$. A tabela 2 apresenta essas informações:

Tabela 2 - Convocações e cooperação entre Anonymous estrangeiros

\begin{tabular}{c|c|c}
\hline $\begin{array}{c}\text { Convocações e cooperação } \\
\text { internacional }\end{array}$ & N & \% \\
\hline Convocação Presencial & 43 & 7,9 \\
\hline E-Participação & 25 & 4,6 \\
\hline Presencial e E-Participação & 24 & 4,4 \\
\hline Cooperação Internacional & 59 & 10,8 \\
\hline Sem convocação & 396 & 72,4 \\
\hline Total & $\mathbf{5 4 7}$ & $\mathbf{1 0 0 , 0}$ \\
\hline
\end{tabular}

Fonte: elaboração dos autores
Isso reforça o caráter hacktivista da Operação, uma vez que a realização de protestos virtuais considerados ilegais, não é incentivada para aqueles que não possuem conhecimentos técnicos suficientes para preservação das suas identidades reais. Além disso, essa conduta converge com o individualismo colaborativo hacker. Isso porque as ações são realizadas, por vezes individualmente e as informações resultantes é que são compartilhadas coletivamente. Desse modo, o público externo era incentivado mais a contribuir na divulgação das atividades do que a participar efetivamente da Operação. Esse apelo ao anonimato também fica evidente no ranking dos perfis mais mencionados ${ }^{43}$. Todos os perfis que ilustram o gráfico 4 se valem de uma identidade virtual anônima:

Gráfico 4 - Top 20 das menções ${ }^{44}$

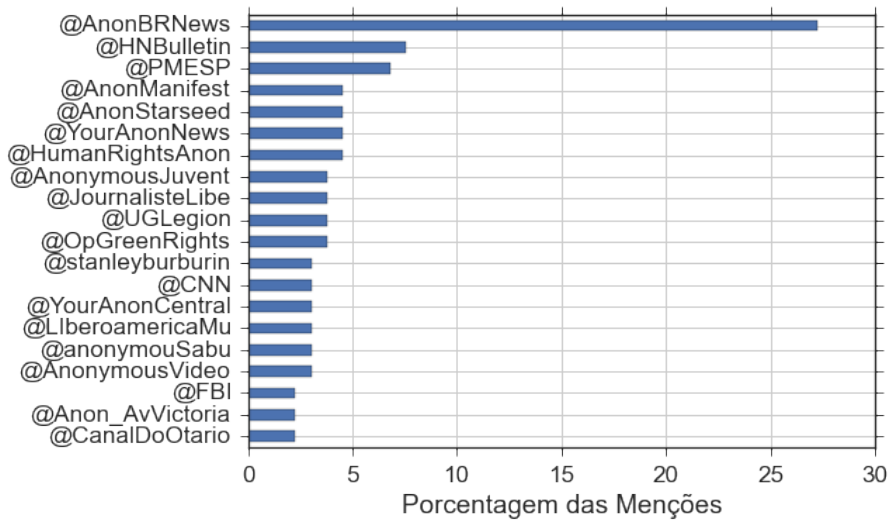

Fonte: elaboração dos autores.

O perfil @AnonBRNews possui o maior quantitativo de menções ( 36 casos $/ 27,2 \%$ ) tanto em decorrência da sua automenção no conteúdo das postagens como também pelas respostas aos tweets de outros usuários, ocasionando em uma menção indireta. O perfil @HNBulletin é o segundo (10 casos/7,5\%). Esse portal de notícias (Hacker News Bulletin) cooperou na atualização diária da lista com os sites-alvo derrubados. Em seguida, vem o perfil @PMESP (09 casos/6,8\%).

\footnotetext{
${ }^{43}$ A menção, no Twitter, é uma conta de usuário precedida pelo @ e identifica tanto um retweet quanto um diálogo com outro perfil.

${ }^{44}$ As exceções são: @PMESP (Polícia Militar do Estado de São Paulo), @CNN (Cable News Network) e o @FBI (Federal Bureau of Investigation).
}

${ }^{41}$ Com exceção de \#Opmundial 2014 (22 casos/4,2\%).

${ }^{42}$ Para mais informações: https://ninja.oximity.com/. 
A maior parte das menções a polícia, assim como em outros tweets que tratam dessa pauta, evidencia críticas negativas. Dentre outras questões, essas postagens expressam repúdio as repressões policiais ocorridas contra ativistas e a divulgação de atividades de hacking. Dentre essas atividades, ocorre o vazamento dos dados pessoais de um policial civil que atirou para o alto em um dos protestos contra a $\mathrm{Copa}^{45}$ e a divulgação do acesso à intranet (rede privada) da Polícia Federal.

O saldo da Operação Hacking Cup foi postado diariamente no site dos Anons. No entanto, a última divulgação ocorreu no dia 19/06, quase um mês antes do final da Operação. No resumo constam ações realizadas em 07/06 (sábado), antes do início da Copa. Segundo a postagem realizada no Twitter, a página da Agência Brasileira de Inteligência (ABIN) foi o primeiro alvo: "Olá, marujos! \#TangoDown na ABIN, pra começar bem a \#OpHackingCup - com @AnonymousJuvent ${ }^{46 "}$. A tabela 3 apresenta o tipo de intervenção ocorrida nos sites-alvo pelo tipo domínio:

Tabela 3 - Intervenção no site pelo tipo de domínio

\begin{tabular}{l|c|c|c}
\hline \multirow{2}{*}{ Tipo de ação } & \multicolumn{2}{|c|}{ Tipo de Domínio } & \multirow{2}{*}{ Total (\%) } \\
\cline { 2 - 4 } & Gov (\%) & Outro & \\
\hline DdoS & 21,6 & 7,9 & 29,5 \\
\hline Deface & 24,5 & 35,3 & 59,7 \\
\hline Leak & 5,0 & 2,9 & 7,9 \\
\hline DDoS e Deface & 0,7 & 1,4 & 2,2 \\
\hline DDoS e Leak & 0,7 & 0 & 0,7 \\
\hline Total & $\mathbf{5 2 , 5}$ & $\mathbf{4 7 , 5}$ & $\mathbf{1 0 0}$ \\
\hline
\end{tabular}

Fonte: elaboração dos autores a partir do site Anonymousbrasil.com ${ }^{47}$

A maior parte das ações foi direcionada a sites de domínio governamental, totalizando 73 casos $(52,5 \%)$. Esses dados sugerem o foco na esfera pública em detrimento do âmbito privado. Isso porque as atividades desempenhadas por órgãos de governo têm um maior impacto sobre

\footnotetext{
45 Id 416.

${ }^{46}$ Id 199.

${ }^{47}$ Disponível em: http://www.anonymousbrasil.com/coluna/resumo-da-operacao-hacking-cup-ophackingcup/. Último acesso em: $15 / 01 / 2015$.
}

a população do que aquelas exercidas por uma empresa. Outros domínios aparecem em seguida, totalizando 66 casos $(47,5 \%)$. Conforme esperado, as ações de negação de serviço (DDoS) e a desfiguração de páginas (Deface) foram as atividades mais recorrentes, constituindo respectivamente, $41(29,5 \%)$ e 83 casos $(59,7 \%)$. Esses dados indicam ainda, o sucesso dos hacktivistas em atividades de desfiguração de páginas, que são preferíveis pelos seus praticantes por explicitarem claramente a mensagem de protesto ao contrário do que ocorre no DDoS. Entretanto, nas Operações em geral, as ações de $D D o S$ são mais recorrentes que o deface pela sua menor dificuldade de execução.

No domingo (08/06), o alvo dos hacktivistas foi a Hyundai, um dos patrocinadores da Copa. "Esteja lá com Hyundai"? Na internet pelo menos não :/ \#TangoDown \#OpHackingCup ${ }^{48}$ ", postou o coletivo após o site sair do ar, brincando com o slogan promocional da empresa (Promoção esteja lá - Hyundai). Nos dias seguintes outros sites foram atingidos e apresentaram instabilidade ou queda: Fundação Procon - SP; Ministério do Trabalho e Emprego; Receita Federal do Brasil; Polícia Militar de SP; Ministério do Esporte; Wise Up; Coca-cola Brasil; Infraero Aeroportos; Ministério do Meio Ambiente, dentre outros.

Por vezes, as postagens que publicizavam essas ações não prescindiam a diversão, isto é, ao espírito Lulz: "\#OpHackingCup \#OpWorldCup DDoS? Amo MUITO tudo isso! \#NãoVaiTerLanche ${ }^{49 ", ~ t w e e t ~ f e i t o ~ a p o ́ s ~ o ~ s i t e ~ d a ~}$ Mc'Donalds apresentar instabilidade junto a um meme sobre o ocorrido.

Outro ponto importante é que a maioria das mensagens apresenta algum tipo de link externo, interativo ou não (89,9\%). A tabela 4 apresenta esses dados:

Tabela 4 - Presença de links externos

\begin{tabular}{c|c|c}
\hline Presença de links & $\mathbf{N}$ & $\mathbf{\%}$ \\
\hline Sim & 492 & 89,9 \\
\hline Não & 55 & 10,1 \\
\hline Total & $\mathbf{5 4 7}$ & $\mathbf{1 0 0}$ \\
\hline
\end{tabular}

Fonte: elaboração dos autores.

\footnotetext{
48 Id 200

${ }^{49}$ Id 238.
} 
Uma parte significativa desses links remete ao perfil da @AnonBRNews no Facebook. Isso se explica pela necessidade de um espaço para ampliação do debate (o Twitter limita as postagens a 140 caracteres) e para repercussão das atividades do coletivo em outras redes sociais. Além disso, o Facebook ${ }^{50}$ tem uma maior popularidade de uso quando comparado ao Twitter, embora o alcance das suas postagens seja menor em razão do algoritmo para classificação dos conteúdos exibidos no Feed de notícias. Outros links direcionam para páginas derrubadas ou desfiguradas e outros estão quebrados (indisponíveis). Sugere-se quanto a uma parte dos links indisponíveis, que se trata de redirecionamentos para páginas (falsas) desfiguradas, que ficaram indisponíveis posteriormente.

\section{Fim de Jogo?}

Com o término dos jogos do mundial, as postagens sobre a Operação diminuíram. As últimas mensagens coletadas, publicadas entre $10 / 07$ e 15/07, versam predominantemente sobre atos de protesto nas ruas e sobre a prisão de ativistas em virtude dessas ações. Além disso, há a convocação para manifestações presenciais em desagravo as prisões.

Em agosto de 2014, um mês após o término da Operação, o coletivo divulgou em seu site, um dossiê interno da EMBRAER (Dossiê Embraer - Desvios de verbas, favorecimento político e superfaturamento), que foi obtido após o acesso ao servidor que hospeda o site dessa empresa. Na postagem, há a denúncia de irregularidades cometidas por funcionários de alto escalão da empresa, tais como o superfaturamento no fornecimento de serviços gráficos, e o link para o acesso direto ao dossiê.

\section{Considerações finais}

Esse trabalho evidenciou como atores políticos não estatais utilizam as redes digitais para o ativismo político se valendo do anonimato para preservação das suas identidades civis.

\footnotetext{
50 O Facebook é o segundo site de maior audiência mundial de acordo com o Alexa Internet Inc., serviço que mede a quantidade de usuários que visitaram um site. Para mais informações: http:// www.alexa.com/.
}

Isso porque atacar alvos poderosos transnacionalmente, através da derrubada de sites ou do vazamento de informações sigilosas, só é possível enquanto as identidades reais dos atores engajados nessas ações (legalmente ambíguas) permanecem desconhecidas. Isto é, a invisibilidade individual fortalece a visibilidade coletiva quando esta é feita sob o manto do anonimato. As Operações articuladas pelos Anonymous, tais como a \#OpHackingCup, também conquista adesões justamente por não haver a necessidade de identificação civil por parte daqueles que nela se engaja. Além disso, essas Operações se fazem na mesma velocidade com que se desfazem, tornando difícil combater e controlar esse tipo de protesto virtual em face dos vínculos temporários entre os ativistas. De modo que eles não buscam "destruir a Matrix" (algo impossível), mas, antes disso, aproveitar as suas falhas para causar pequenos ou grandes impactos, ainda que temporários. Desse modo, esses atores sem revelar quem são, buscaram através de ferramentas digitais transgressivas, chamar a atenção para questões que passaram despercebidas na grande mídia: a repressão policial nas manifestações durante a Copa do Mundo de 2014.

Os Anonymous, portanto, por seu nível de fluidez e horizontalidade, são atores que evidenciam novos repertórios de ação política no espaço virtual. Afinal, mostra-se difícil combater e controlar uma ideia desterritorializada, que se forma numa rede dissolvida em outras inúmeras redes, tornando-a tão difusa quanto o controle presente no contexto do capitalismo cognitivo, no qual os bens intangíveis são extremamente valiosos para reprodução do capital.

É importante destacar que em face do limitado número de Operações analisadas, (apenas a \#OpHacking Cup) e o quantitativo de perfis (apenas @AnonBRNews), é necessária cautela em relação aos dados apresentados. Além disso, é importante o foco nas atividades da rede além dos períodos das Operações e das atividades com caráter hacktivista, para que se evidenciem outros tipos de engajamento político por parte desses indivíduos. Mostra-se fundamental também extrapolar as análises para o espaço offline, haja vista que os Anonymous também atuam em atos presenciais, igualmente se valendo da máscara de Guy Fawkes, símbolo do coletivo. 
Esse trabalho espera chamar a atenção para dois principais aspectos: 1) os novos repertórios de ação política na sociedade informacional; e 2) o anonimato como estratégia política frente ao controle nas redes informacionais.

\section{Referências}

ASSANGE, Julian et al. Cypherpunks: a liberdade e o futuro da internet. São Paulo: Boitempo, 2012.

BRAFMAN, Ori e BECKSTROM, Rod. Quem está no comando? A estratégia da estrela do mar e da aranha. Rio de Janeiro: Campus, 2007.

CLEAVER, Harry. Zapatistas e a teia eletrônica de luta. Lugar Comum, v. 4, p. 139-163, 1998.

COLEMAN, Gabriela. Nossa esquisitice é livre. In: SILVEIRA, Sergio Amadeu da; JOSGRILBERG, Fabio B. (Orgs.). Tensões em rede: os limites e possibilidades da cidadania na Internet. São Paulo: Metodista, 2012.

FLICK, Uwe. Introdução à metodologia de pesquisa: um guia para iniciantes. Porto Alegre: Penso, 2013.

GERRING, J.. What Is a Case Study and What Is It Good for? American Political Science Review, Los Angeles, v. 98, n. 2, p. 341-354, 2004.

LEMOS, André; SEARA, Simone; PÉRSIO, Wilson. Hackers no Brasil. Revista contracampo, $n^{\circ} 06, p$. 21-42, 2002.

Cibercultura Remix. In: Seminário Sentidos e Processos. São Paulo, Itaú Cultural, agosto de 2005. Disponível em: <http://www.facom.ufba.br/ciberpes quisa/404nOtF0und/404_46.htm>. Acesso em: 29 out. 2012.

LESSIG, Lawrence. Code and Other Laws of Cyberspace. New York: Basic Books, 1999.

LEVY, Steven. Hackers: Heroes of the Computer Revolution - 25th Anniversary Edition. Sebastopol: O'Reilly Media, 2010.

MACHADO, Murilo Bansi. Anonymous Brasil poder e resistência na sociedade de controle. Bahia: EDUFBA, 2013.

MILAN, Stefania. "The Guardians of the Internet? Politics and Ethics of Cyberactivists (and of their Observers)", Methodological and Conceptual Issues in Cyber Activism Research, National University of Singapore, 2013, pp. 167-191. Disponível em: <https://citizenlab.org/wp-content/uploads/2012/08/
NUS_Session-6_Stefania-Milan.pdf>. Acesso em: 02 set. 2014.

MANION, Mark; GOODRUM, Abby. Terrorism or civil disobedience: toward a hacktivistic ethic. Computers and society, v. 30, n. 2, p. 14-19, jul. 2000.

OLSON, Parmy. Nós somos Anonymous: por dentro do mundo dos hackers. São Paulo: Novo Século, 2014.

PARRA, Henrique. Soc. e Cult., Goiânia, v. 15, n. 1, p. 109-120, jan./jun, 2012.

PIMENTEL, Tiago; SILVEIRA, Sérgio Amadeu da. Cartografia de espaços híbridos: as manifestações de junho de 2013. Disponível em: <http://interagentes. net/?p=62>. Acessado em: 03 jun. 2014.

SAMUEL, Alexandra Whitney. Hacktivism and the future of political particiption. 2004.273 f. Tese (Doutorado em Ciência Política) - Departamento de Governo, Universidade Harvard, Cambridge, Massachusetts.

SILVEIRA, Sérgio Amadeu. Redes cibernéticas e tecnologias do anonimato. Comunicação \& Sociedade, Ano 30, n. 51, p. 113-134, 2009.

Ciberativismo, cultura hacker e o individualismo colaborativo. Revista USP, v. 1, p. 28-39, 2010.

Poder e anonimato na sociedade de controle. In: ; JOSGRILBERG, Fabio B. (Orgs.). Tensões em rede: os limites e possibilidades da cidadania na Internet. São Paulo: Metodista, 2012.

VEGH, Sandor. Hacking for democracy: a study of the internet as a political force and its representation in the mainstream media. 2003. $349 \mathrm{f}$. Tese (Doutorado em Estudos Americanos) - Departamento de Estudos Americanos, Universidade de Maryland.

WONG H. Wend, BROWN Peter A. E-Bandits in Global Activism: WikiLeaks, Anonymous, and the Politics of No One. Perspectives on Politics, v. 11, p.10151033, 2013.

WRAY, Stephen. Electronic civil disobedience and the world wide web of hacktivism: amapping of extraparliamentarian direct action net politics. Switch: New Media Journal, n. 10, 1998. Disponível em: <http://switch.sjsu.edu/web/v4n2/stefan/index.html>. Acesso em: 05 jun. 2014.

YIN, R.K. Estudo de caso: planejamento e métodos. 3. ed. Porto Alegre: Bookman, 2005. 


\section{Sites consultados}

"Anonymous lidera ativismo digital nos protestos, diz estudo", Folha de S. Paulo, 2013. Disponível em: <folha.uol.com.br/cotidiano/2013/07/1310892anonymous-lidera-ativismodigital-nos-protestos-dizestudo.shtml>. Acesso em: 10/11/2014.

"Caminhando e teclando", Observatório da Imprensa, 2014. Disponível em: <http://www. observatoriodaimprensa.com.br/news/view/_ed798 caminhando_e_teclando>. Acesso em 03/12/2014.

"Constituição americana", Embaixada dos Estados Unidos, 2013. Disponível em: <http://www.mspc.eng. $\mathrm{br} /$ temdiv/const_usa01.shtml\#eme_1>. Acesso em: 04/03/2015.

Lei $n^{\circ} 12.737 / 2012$. Disponível em: <http://www. planalto.gov.br/ccivil_03/_ato2011-2014/2012/lei/ 112737.htm>. Acesso em: 04/03/2015.

Lei $n^{\circ}$ 2330/2011, disponível em: <www.planalto.gov. br/ccivil_03/_ato20112014/2012/Lei/L12663.htm>. 